Bio:

JANETTE HUGHES is an assistant professor at the Faculty of Education, University of Ontario Institute of Technology. She teaches primary/junior language arts and intermediate/senior English methodology courses. Her research is in the area of multiple literacies and explores technological transformations of literacy.

\begin{abstract}
:
Through an examination of digital poetry explorations created by the researcher based on conversations with four Canadian poets, this paper explores the convergence of poetry and new media and attempts to address what happens when the pedagogical ideals outlined by the poets are represented digitally. The poets and researcher discuss the affordances the digital poetry explorations might offer a potential reader or aspiring writer.
\end{abstract}

\title{
Poetry and New Media: In Conversation with Four Poets
}

Overview of the Research

My research takes place at the intersection of (1) poetry, (2) digital learning environments, and (3) multiple literacies. It explores the boundaries of what can be done with poetry in schools, and especially in an online, digital environment. The study is based on interviews with prominent contemporary Canadian poets in an attempt to explore the nature of poetry, the teaching and learning of poetry, and the potential role of new media. The interviews I conducted with Cornelia Hoogland, Penn Kemp, John B. Lee, and Molly Peacock, offer varying perspectives on poetry and the teaching and learning of poetry. Cornelia Hoogland < http://publish.edu.uwo.ca/cornelia.hoogland/ $>$ is an award-winning writer (poet and playwright) and scholar who currently teaches at

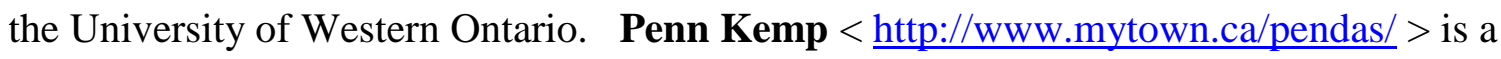
Canadian poet, playwright, novelist and sound poet. As a sound poet and workshop leader, Kemp has performed in arts festivals around the world, giving readings and 
workshops, often as writer in residence. John B. Lee <

http://www.blackmosspress.com/pages/Author\%20Pages/Lee/Lee.html> is a Canadian author and poet who is presently Poet Laureate of Brantford, Ontario. He has received more than 60 prestigious international awards for poetry. Molly Peacock < http://www.mollypeacock.org/ >, a poet and a creative nonfiction writer, is the author of six books of poetry, including Cornucopia: New \& Selected Poems. Former Poet-inResidence at the American Poets' Corner (Cathedral Church of St. John the Divine, New York City) and former President of the Poetry Society of America, Peacock was also coeditor of Poetry in Motion: 100 Poems from the Subways and Buses (1996), a collection of the popular poems displayed on placards in New York City's subways and buses.

In the first stage of interviews the context of expert opinion on the nature of poetry and poetry teaching and learning was established. In the second stage of interviews, the poets responded to a set of digital poetry explorations ${ }^{1}$ that $\mathrm{I}_{\text {created }}$ based on their ideas about and views of poetry. They also viewed segments of video from the first set of interviews with the other poets that illuminate how each poet views poetry and poetry teaching and learning. For example, one digital poetry exploration focuses on the oral reading of a poem by eight different readers of different ages, ethnic backgrounds, and genders, and includes the poet herself (see Figure 12 or http://faculty.uoit.ca/hughes/Research/multiple.html).

This exploration grew out of the poets' view that each reader offers his or her own inflection, drama and interpretation and the contention that poetry needs to be read aloud

\footnotetext{
${ }^{1}$ The kind of Flash interactives I have designed and created are sometimes called "interactives" or "learning objects," however, I find both terms problematic. There is no clear definition of what "interactivity" means but it is something I discuss in this paper. The term "learning object" begs the question, "what is not a learning object" and is therefore too vague. I use the term "poetry exploration" because I think it evokes its underlying experiential potential.
} 
because the meaning of a poem can shift depending on the way it is read. The poetry explorations are intended to allow the researcher to explore and play with poetic conventions identified by the poets, but they might also serve as examples of potential teaching tools. Such a multimodal approach, (with an emphasis on the aural, in this case), can offer new and powerful ways to think about and understand poetry (LuceKapler, 2003). The poetry explorations were stored in a digital environment published online that allowed the poets, and the public, to see the poets' poems, their interview clips and the poetry explorations (see http://faculty.uoit.ca/hughes/Research/poetry.html).

Through an examination of the poetry explorations, the poets and researcher discussed the affordances the digital poetry explorations might offer a potential reader or aspiring writer. In our conversations about exploring poetry with students, the poets identified two essential pedagogical aims or ideals: 1) poetry needs to be read aloud and lifted off the page through performances of various kinds, and 2) students need time for sustained and playful engagement with the poem. In this paper I explore the convergence of poetry and new media and I attempt to address what happens when the pedagogical ideals outlined by the poets are represented in a digital environment. Poetry in a New Media Age

Although people have always used rich and innovative ways to read and teach poetry, the traditional mode for teaching poetry has been through print text. The dominant model of poetry teaching has been to focus on finding one meaning to be dissected or a content to be apprehended. In today's world, literacy includes how texts are produced and how multimodal forms of representation work together to convey meaning. Most poetry anthologies, especially those designed for intermediate and senior 
students, do not include visual images and typically are not accompanied by compact discs to facilitate listening to the poems or viewing performances of the poetry. A notable exception is former United States Poet Laureate Robert Pinsky’s Favourite Poem Project produced on DVD, which features people from all walks of life reading and commenting on their favourite poems. Given the burgeoning technological revolution, it seems safe to predict we will see more and more literature being offered through ebooks, CDs, DVDs and iPod or MP3 downloads.

Kress (2003) argues that very soon the screen will govern all of our communication practices and language use. Students will understand language use within an electronic medium. As Pahl and Rowsell (2005) point out, "Language is not, and clearly will not be, printed texts with incidental images, but instead texts of all kinds with colour, different fonts, on monitors or mobile phones with sound, gesture and movement" (p. 4). In digital environments different modalities - aural, visual, gestural, spatial and linguistic - come together in one surround in ways that reshape the relationship between printed word and image or printed word and sound (Jewitt, 2006).

This study is an examination of the transformation of traditional print text or conventional literary poetry, specifically lyric poetry, typically taught in the classroom as it enters a multimodal, multilinear new media environment. Some of the questions that emerge from a new media treatment of a poem include: How might poetry be experienced in a digital environment? What are the implications for students writing their own poems? How is the poem affected by the means of its delivery? The change in the materiality of text inevitably changes the way we read or receive the text and has important implications for the way we construct or write our own texts. Dobson (2005) 
points out that "our writing tools - whether chisel and stone, reed pen and papyrus roll, press and vellum, typewriter and paper, or keyboard and computer screen-necessarily influence the way we compose and respond to text" (p. 126). She notes that different types of technologies allow certain kinds of thinking while discouraging other kinds. She also points out, however, that although "new technologies modify human ways of knowing and being" it is a reciprocal relationship because human ways of knowing and being also "bring about changes in technology. We are, after all, both agents and subjects of change" (p. 127).

When I discuss my research with others I often get a reaction of surprise at the pairing of poetry and technology. Interestingly some people still equate the computer with an impersonal machine, a notion shared by many (Armstrong \& Casement, 1998; Ellul, 1990; Stoll, 1995), who have argued that reading on the screen removes the sense of intimacy we have with a book. Of course, there was a similar uproar over the advent of the printing press, which many felt put a greater distance between the poet and the reader. However, as Gioia (2004) points out, the mass production of the printing press may "have desacralized the book, but it did not destroy the magical aura of the literary work, only transferred it" (p. 45). Contrary to the notion that electrons agitate is the idea that bringing the poet to the reader through videotaped commentary and oral readings actually brings us closer to the poet in a more personal, intimate, immediate way. In the next section I turn my attention to a description and analysis of the digital explorations that I created in an attempt to address the comments and ideas the poets expressed during interviews.

The Digital Poetry Explorations 
A primary goal of this research was to explore how poetry and new media might speak to each other. The materiality of the computer and the Web offer new ways of representing poetry and, keeping the poets' comments about the teaching and learning of poetry in the forefront, it was my intention to create digital poetry explorations through which I might engage in multimodal ways with some of the concepts that were raised in the interviews. In part, the digital explorations are playful because they exist in a draft form. The poetry explorations were created in an attempt to explore some of the ideas of the poets, in order for them to be discussed and critiqued. They have not been produced in a polished form. In our conversations about reading poetry with students, the poets emphasized the importance of hearing the poem read aloud, the need for sustained engagement with the poem, and time to probe for an initial response and then for deeper meaning through discussion. The current design of the digital explorations is intended to reflect those pedagogical aims. What follows then, is an examination of some of the poetry explorations and an analysis of what affordances they might offer a potential reader or aspiring writer.

Exploring Poetic Structure and Conventions 
Drawing on the notion of playfulness in connection with the exploration of poetry I chose one of Hoogland's playful images to examine the concept of disjunction - the leap from one semantic, discursive or figurative plane to another. Hoogland (2005) points out that "poetry is disjunctive in the sense that it is always moving, always unpredictable, shifting, it dislocates its meanings, it sets up a trope and challenges it, and alludes to its own meanings." Hoogland's reference to yellow Jello in a poem about war creates a jarring effect and I decided to play with this idea using new media (see Figure 1 or http://faculty.uoit.ca/hughes/Research/jello.html ). In the poetry exploration the reader mouses over the coloured dots to change the colour of the Jello in the bowl. At the same time, the line from the poem, "colouring their hair (colour), their

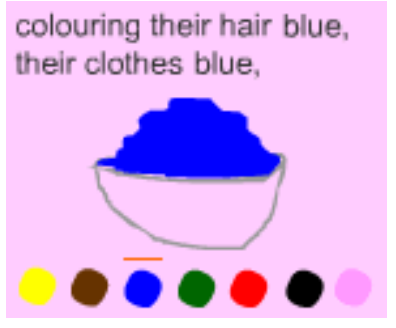

Figure 1. clothes (colour)," also changes to match the chosen colour. The effectiveness of the exploration lies in the combination of the words with the image as they work together to offer insight regarding the appropriateness of the poet's choice.

Another way that the digital poetry explorations facilitate a visual understanding of the poem is through a digital exploration of poetic form using Peacock's (1989) poem, "That Leaf." We use language not only to communicate but to paint as well, and poetry, more than other genres, relies on the use of white space for expression. Poetry is a visual artifact and keeping in mind Peacock's assertion in an interview that it was the beauty of the poem's form, its small size and its white space, that attracted her to poetry in the first place, I created a poetry exploration that examines how a poem might change when viewed as a prose piece or divided into stanzas where stanzas were not originally 
included. (see Figure 2 or

http://faculty.uoit.ca/hughes/Research/prose.

html). The exploration encourages students

to think about how each version changes

their understanding of the poem. Of course,

anyone could do the same exercise using the

poem printed on a page, first in prose, then in

stanzas and finally, as written. The

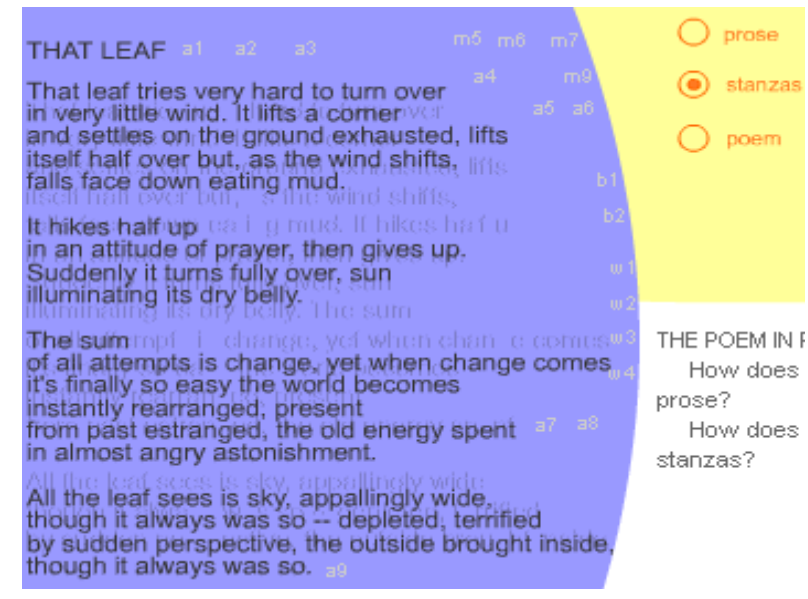

Figure 2.

advantage of experiencing it in a digital environment is the ease with which the viewer can alternate between each version on one screen, which lends it an immediacy not available in print form on three different sheets of paper.

Another example of how new media might invite the reader to examine poetic form in a new light is the poetry exploration based on line breaks in Hoogland's (2004) poem "Normal, Blessed Normal" (See Figure 3 or http://faculty.uoit.ca/hughes/Research/breaks.html ). By mousing over the coloured dots, the reader sees seven different structural versions of one stanza in the poem, including the stanza as written. Returning to the idea of the poem as a visual artefact, the very act of changing where the line break occurs has a visual impact, and can therefore change the tone of the poem. This exploration makes the reader think differently about where the emphasis falls and also prompts us to explore the poet's decisions. Such an exploration not only promotes the kind of deep engagement with the poem that the poets suggest is a necessary ingredient for a successful poetry lesson, but also encourages the reader to see and understand the poem in different ways. Prolonged, deep engagement with the poem 
has important implications for writing as well because it gives writers new windows into the poem, which can provide insights when reading or writing poetry.

In a final example of how new media might help promote this type of visual exploration of the poem while at the same time begin to explore the meaning of a poem, I turn to Peacock's idea about teaching poetry by isolating the nouns, or verbs or adjectives and adverbs in a poem. Peacock advises teachers to begin the study of a poem by having their students identify all of the nouns, for example, in the poem. She argues that students can understand the essence of poem by considering the interrelationship of the nouns. The same can be done with verbs or adjectives. According to Peacock, this type of exercise helps to take the mystery, and therefore the fear, out of poetry for those who find poetry initially daunting, in the hope that eventually it will be the "density and intensity" that they will come to appreciate. In the poetry exploration based on Peacock's comments, either the nouns, the verbs or the nouns and verbs together appear without the rest of the poem's text (See Figure 4 or http://faculty.uoit.ca/hughes/Research/nouns.html ). When you look at the nouns in the poem as they appear in this exploration, it is like a new poem has been created. Employed in this way, new media seems to encourage the reader to see poetry in different ways, leading the reader to reflection and action, perhaps in his or her own writing. 
begins with a video of two children walking backwards on a railroad track. Lee's own response as reader or viewer of this new text is that the linking of the literal images with text serves to shape the reader's experience by "shifting the ground prematurely" into an interpretation so that nothing is left for the reader to imagine.

Lee argues that the way in which the experience and the interaction are influenced and shaped by context and content is "so profound, so ineluctable, so influential" that it reminds him of how we "influence thinking by placing certain filters, assumptions, preconceptions between the person/responder and the work of art" (JBL:email). Lee believes that the visual information we take in by looking at a visual image "often excites subliminal responses," which he doesn't believe is true of literature because "we process language differently" (JBL:email). Therefore, he argues, "the visual juxtaposed to the poem requires an integration of two very different kinds of experience" (JBL:email).

In a second digital exploration that links visual images of war to one of the stanzas in Hoogland's (2004) poem "Normal, Blessed Normal," the lines are superimposed over a series of five still images in sepia and faded colour (See Figure 6 or http://faculty.uoit.ca/hughes/Research/images.html ). The images of buildings crumbling or already destroyed by bombs

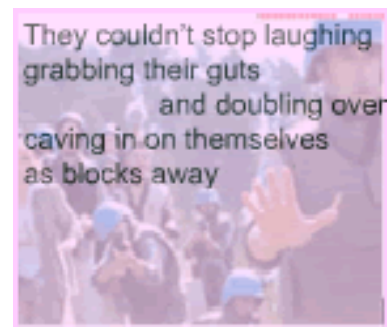

Figure 6. are intended to illuminate, illustrate and extend the lines, “They couldn't stop laughing/grabbing their guts and doubling over/caving in on themselves/as blocks away/buildings doubled and caved." Each line of the stanza appears as it is read by Hoogland and remains on the screen, as each new line, accompanied by a new image, is added to the screen. This is a different way of experiencing images, 
which, in a print text, would remain static on the page. The succession of images that are similar and could represent any war torn city, serves to emphasize the repetition of war - we have heard and seen this story before. All of the poets indicated that the images changed too quickly (with the exception of the last image which remains on screen, each image stays for three seconds) for them to get a satisfactory look at them. Coupled with the fact that they might be looking at the poet as she read or at the words as they appeared on the page, they suggested that there was perhaps too much going on at once. Despite the concerns about too much happening all at once, I am not convinced that viewing words and images converge on a screen while listening to the same words being read by the poet would be equally overwhelming to someone belonging to the 'Net' generation Nevertheless the notion that overexposure to the world of images, in particular television and video games, promotes overstimulation and has led to increasing rates of attention deficit disorder and other symptomologies is quite common (Luke, 2003; Sullivan, 2000).

In response to my work I have, on occasion, also heard the argument that because visual imagery is so dominant in today's society, we should allow the words of poetry to do most of the work. If we view the image as a cultural tool for this generation however, are we not limiting their repertoire for making meaning by insisting that the visual mode in some way detracts from the poetry reading experience? Perhaps better chosen images or better timing or even just better design is the issue. It is not a simple task to join visual images with words. It requires that the creator possess a new or different set of skills, including visual 
artistry and imagination. It is certainly a more complex task to find or create images that move beyond the literal. However, it is not my goal to try to resolve the controversy about visual versus textual imagery, or even to take a personal position on it. Instead, it is my intention to open a discussion about the controversy so that the reader might explore it through the digital explorations.

The notion that a reader's attention may become distracted by the visuals or that the visual images foist a certain predetermined interpretation on the reader, resulting in the collapse of any critical capacity s/he might have developed, seems to be a common one. I do not believe that images put readers at risk by not encouraging critical engagement with a poem. I am not convinced that the inclusion of visual images absolves the reader from doing important interpretive work. Perhaps the work is just of a different type. Visual images combined with print text have long been regarded as antiintellectual in some literary circles. Many people still dismiss a book with illustrations as less serious than a print-exclusive text, a notion reflected in the reluctance many teachers still feel to allow their students to read comic books or graphic novels in class. This is unfortunate because adding visual or auditory components to poetry opens up new ways of using language and experiencing literature.

A poem accompanied by visual images can be seen as a new text, a different way of performing the poem. As such the images cannot be seen as separate from the poem. This begs the question, how does a poem's medium affect its status as a poem? Can it not maintain its innate literary quality, despite the difference of its presentation? Isn't a digital performance of a poem just another medium for expressing the same idea? In this way new media tools can be viewed in the same way an artist would deliberate the 
choices available, for example, whether to use sculpture or paint, and if paint, then oil, acrylic or watercolour. Gioia (2004) argues that "no poet is required to work in only one form" and reminds us of Pound and Cummings who "frequently crossed the borders between auditory and visual poetry" (p. 25). He points out that "the aesthetic of each form is different, and under the pressure of electronic culture, artists are pushing the forms farther apart as the emergence of new forms like Spoken Word and slam poetry demonstrates" (p. 25). I would add hypertext and flash poetry to Gioia's list of recent innovations in poetry. Technological innovations have traditionally met with resistance. It is not uncommon, as Kellner (2000) points out, for new technologies to evoke a polarized response. In fact, this has been the case throughout history, whenever a new technology, such as the printing press, film, radio, TV and now computers, has emerged (p. 215).

The question is not only whether to combine poetry with visual images. We also need to examine the kinds of images that may or may not be effective from a pedagogical perspective. Peacock "loved" the visual image of the two children walking backwards on the train track in the poetry exploration for Lee's poem, but she suggests more of an integration of words with the images as well as choosing the visual images carefully. Hoogland argues that it might be more useful to provide contrasting images rather than to try to duplicate the verbal images in a poem. Of course this is more difficult to do well and requires a more complex set of skills but by doing so, she points out, the reader would be asked to consider how the images are different and alike, which helps her/him "to think relationally, emotionally, imaginatively" (CH:email). Providing contrasting or even contradictory images where words and pictures oppose one another serves to disrupt 
the reader's expectations, thus requiring more of the reader. Hoogland further suggests that it might be helpful to create an opportunity for the reader to "select from among images those which appeal to them and then to try to write that image (importantly not asking linear reasons why but to respond in a writerly way without thought to reason and justification)" (CH:email). In response to her suggestion, I designed a digital exploration that does just that (see Figure 7 or http://faculty.uoit.ca/hughes/Research/multimedia.html at the bottom). The reader is presented with a series of images related to one stanza in Lee's poem, “The way the window glass/shatters around you/in a dangerous puzzle of cutting reflections," and they are prompted to view the images and consider which image most closely captures their own impression or response to the poem. Lee's response to the initial idea was positive. He comments, "I like your idea of giving students a choice

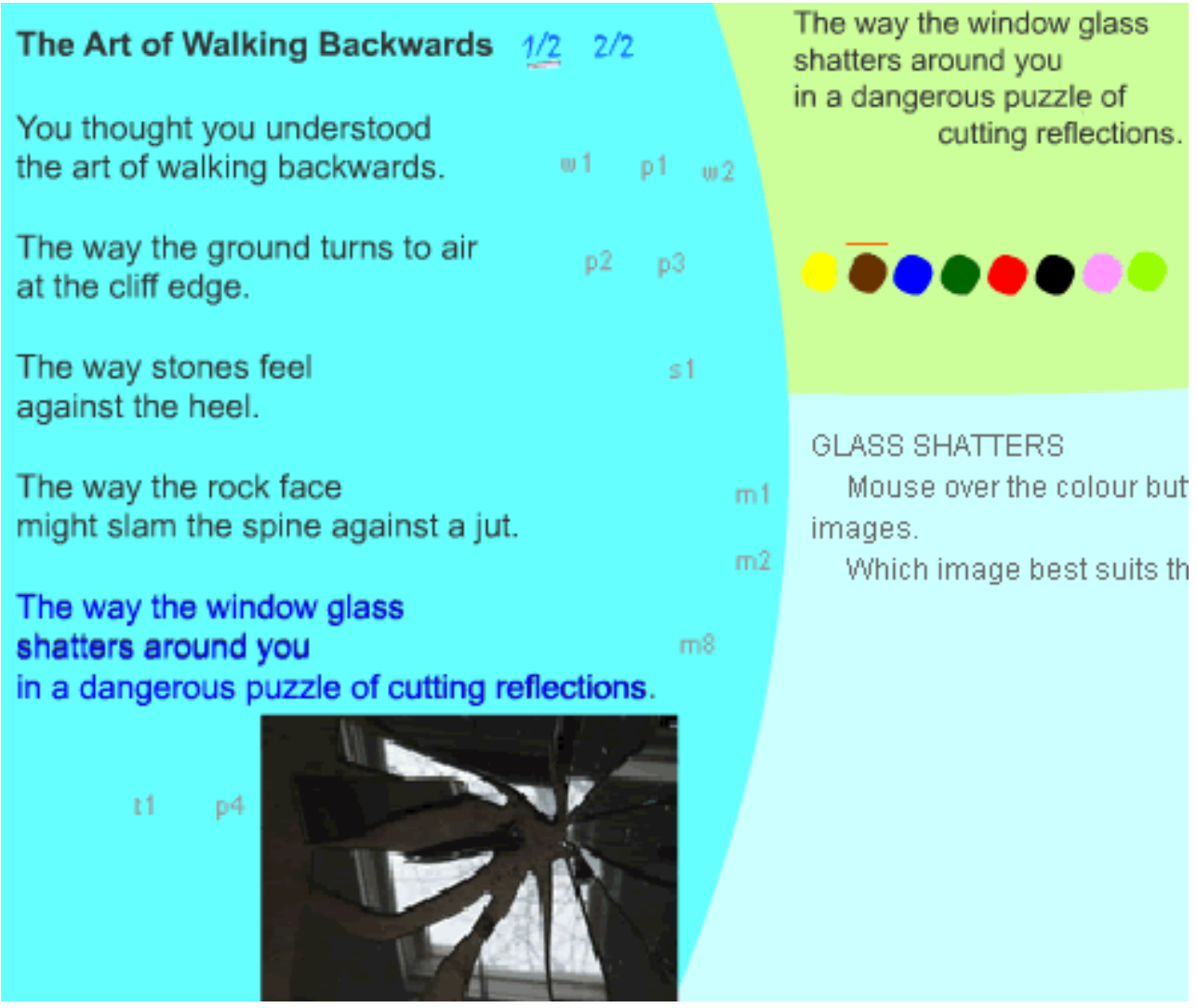

Figure 7. 
between images because then in the conversation about the visual imagery, they are required to "see" the poem" (JBL:email). To build on Lee's idea, a drawing tool could be added, which would enable the reader to contribute his or her own image to the choices already provided. Such a tool would add a higher level of interactivity - the reader is cocreating images for the poem rather than passively accepting the images offered.

Lee confesses that as a reader, he would "much prefer the poet simply reading without the benefit of these images" (JBL:email). At poetry readings, however, the poet typically sets the stage with a story or context, which brings new images to bear on the poem that perhaps changes how the listener understands the poem. Some poets use sets and costumes, which are physical images, in performances of their poems. The set for Peacock's one-woman show, for example, consists of long, shimmering pieces of blue and green fabric that serve to delineate different playing areas on the stage. Following Lee's argument, then, might these practices be seen as diminishing the poems themselves? From the perspective of a teacher Lee does see some value in using visual images in conjunction with a poem, acknowledging that "the reading with the visuals provides a fascinating experience that establishes the importance of how we take things in" (JBL:email). He argues that such a coupling provides the reader with an opportunity to rub his/her ideas up against the version provided in the exploration. For Lee, this particular digital exploration has pedagogical potential because it affords the reader the opportunity to enter into a dialogue with the poem, which is an ideal promoted by all of the poets. Rather than accepting the images uncritically, the reader is encouraged to think more deeply about how the 
visual images might enhance or contest their reading and understanding of the poem. A new relationship between words and visual images that has emerged as a result of the digital age can be summarized as synergy (Dresang, 1999). As Dresang points out, synergy exists when words and pictures merge. She argues that "more and more, authors, illustrators, and publishers of books are choosing the synergistic relationship of words and pictures as the preferred means to convey meaning" (p. 88). Of course, such a relationship can be more easily facilitated in a digital environment. To return to Peacock's comment that it might be effective to somehow integrate the words and images, I have designed three

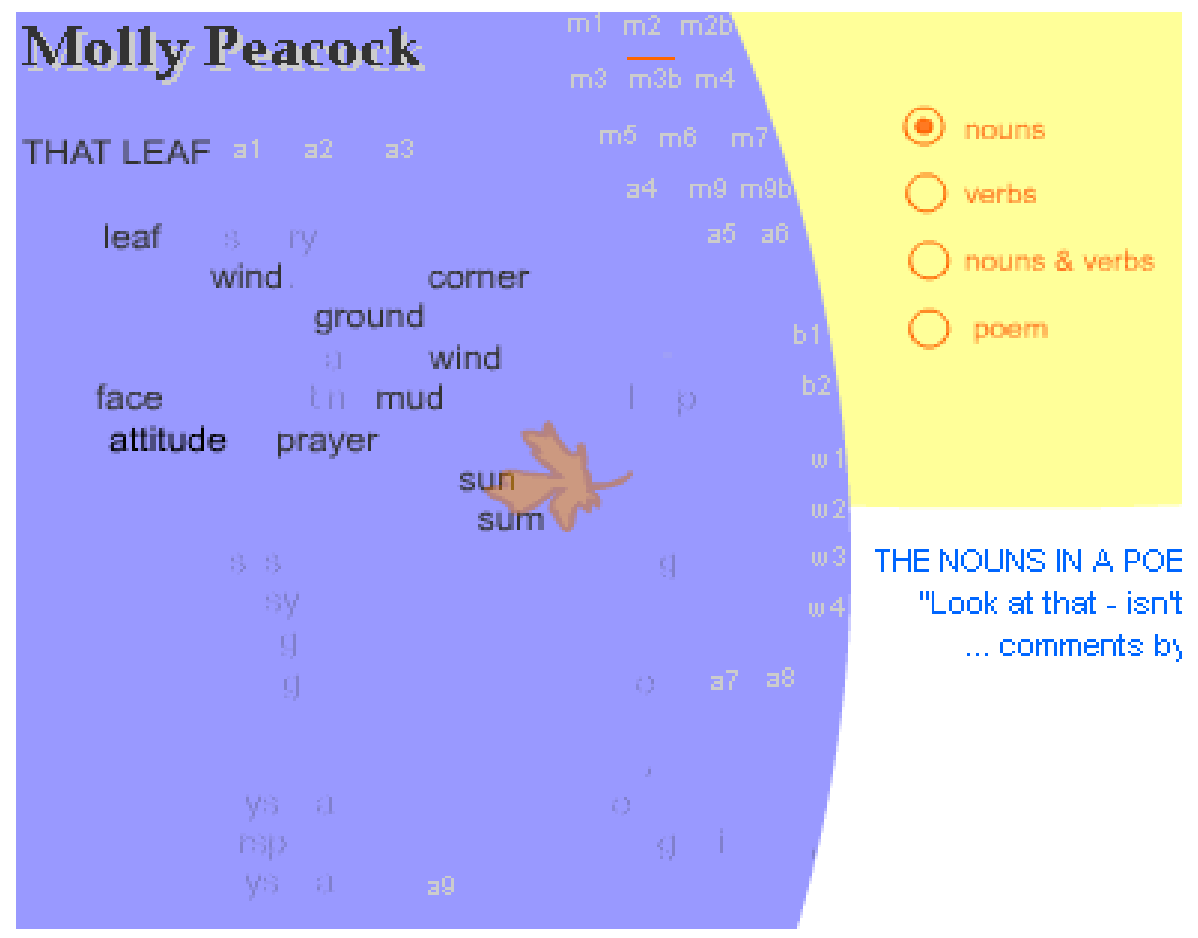

Figure 8 .

possible ways of moving in this direction. A simple example is shown in Figure 8 or see http://faculty.uoit.ca/hughes/Research/nouns.html ). In this digital exploration that builds on the idea of examining the nouns in the poem, an orange 
leaf gently falls from side to side and leaves behind each of the nouns as it falls. This serves to emphasize Peacock's point that the visual image created by isolating the nouns in the poem suggests a falling leaf. Another version would be to have each of the nouns fall gently into place on screen, which might mirror the movement of the leaf. Yet another way to design the digital exploration would be to have each of the nouns in the poem slowly appear on screen sitting on a leaf, perhaps over a ten second period. A third alternative would be to have the nouns positioned in the shape of a leaf, like a concrete poem. Digital technology offers the designer or poet a number of options for merging words and visual images. Oral Readings and Poet Commentary "Sound isolates, sound incorporates" (Ong, 1982, p. 71).

The poets remind us that sound, or music as Peacock calls it, is essential to poetry. The medium of poetry has traditionally been the human body in live readings, however, the emergence of new technologies such as the telephone, the phonograph, the radio, the microphone, the loudspeaker and more recently, digital recorders has allowed us to expand poetry's reach (Sapnar, 2003). All of the poets in the study were particularly pleased with new media's capacity to bring the poet and the poem together, both through the oral readings and through the commentary the poets offer about their poems, poetry teaching and learning, and poetry in general.

Collins (2004) asserts that the poetry reading offers a double connection, "one with the poet who stands up from the page and delivers, and another with the audience united by a common interest" (p. 3). He points out that in the oral 
reading, poet and audience take on a visibility that is not found in the "silent transaction of the page" (p. 4). Collins is talking about a live reading rather than a recorded or digital reading, however, as Ong (1982) contends, our era of secondary orality has generated a strong group sense because listening to spoken words form hearers into a genuine audience. Further, he argues that secondary orality "generates a sense for groups immeasurably larger than those of primary oral culture - McLuhan's 'global village' and, unlike those in a primary oral culture who had to rely on speaking and listening because no other alternative had presented itself, in an era of secondary orality we are "groupminded selfconsciously and programmatically" (p. 134). Collins suggests that "to sit in a room with others and witness a breathing poet saying his or her poem aloud provides a relief from the isolation of print, not to mention more existential feelings of estrangement" (p. 4). What a digital reading provides, in many cases, is the poet's voice, which directly refutes the postmodernist notion of the 'death' of the author. On the contrary, hearing the poem read by the poet reminds us of its origins and helps us to understand its meaning according to the poet. The oral reading turns authorship into a performance, and as Collins points out, "may even be said to re-establish the authority of authorship in the face of its downsizing by the academic industry" (p. 4). 


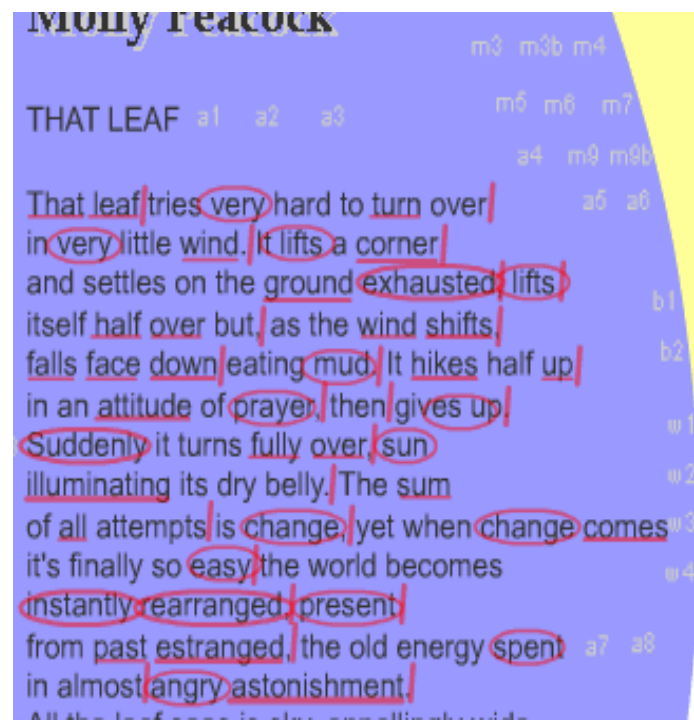

Figure 11 .

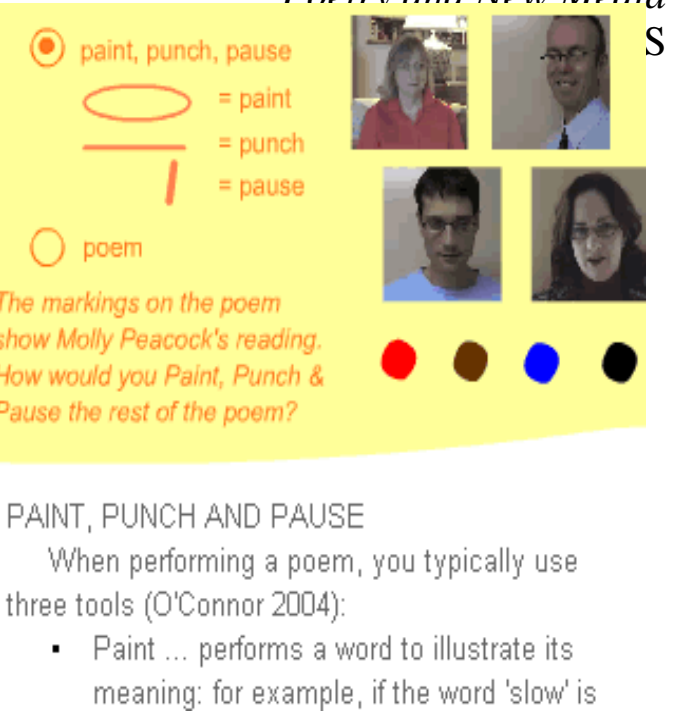

To

illuminate the idea that a reading is a performance and an interpretation, one of the digital explorations examines Molly Peacock's reading of her poem "That Leaf" (See Figure 11 or http://faculty.uoit.ca/hughes/Research/paint.html ). Using O'Connor's (2004) performance tools - paint, punch and pause - the reader can visually see as well as hear how the poet uses these tools as she performs the poem. Again, as Lee reminds us, the poem is a visual artifact and a poem's arrangement on the page provides the reader with direction, much the same way a musical score gives direction to a musician. Punctuation and line-breaks offer the reader cues as to how the poem should be read aloud. Some poets pause at the end of each line in order to emphasize the first word in the next line, while others read through the lines and pause according to punctuation. Cadences in the language also steer an oral reading. Long words lengthen or extend the lines while monosyllabic words do the opposite, just as repeated use of long vowels serve to elongate words and slow the reader down and repetition of short vowel sounds speed the reading up. The choice of words themselves, as well as how 
they are positioned in a line, helps determine whether or not the word will be 'punched' (emphasized) or not. Poets also 'paint' words by performing the word in a way that illustrates its meaning. In Peacock's reading, for example, she utters the word "exhausted" with a heavy sigh. Through a close examination of this digital exploration, the reader should begin to observe that when a poem is read aloud, choices the reader makes (in tone of voice, emphasis, pauses) can affect the listener's understanding of the poem.

Multiple Readings

In the digital exploration just examined and in a similar exploration developed for Hoogland's poem "Normal, Blessed Normal," the reader can compare the oral readings of several different people (See Figure 12 or http://faculty.uoit.ca/hughes/Research/multiple.html ). These

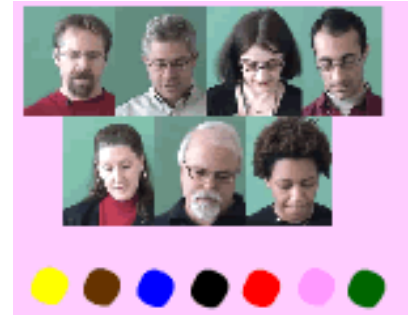

Figure 12. CH:m5 readings are infused with the personalities of each reader. Whether we realize it or not, we offer our interpretation of a poem through our oral reading of it. We make choices about which words to emphasize and these choices affect the meaning of the poem. This exploration reminds us how hearing something read aloud helps mediate meaning making. These two digital explorations afford the reader an opportunity to listen to the readings, and perhaps using O'Connor's notation exercise, to record the way the poem is performed in order to consider or even discuss with others, how the poem was rendered and how each reading promotes or detracts from his or her own hearing and understanding of the poem. Such an exploration prompts the reader to consider how poetry is read aloud and 
to make connections between the poem as it appears on the page (with its linebreaks, rhyme scheme, punctuation and enjambment) and the way it is performed through a person's voice.

Revisiting Poetry in a Digital Age

Experiencing poetry in a multimodal digital space draws on a number of modalities (visual, audio, gestural, linguistic, spatial) and adds layers of meaning that might not be conveyed in a strictly print format. To summarize, the digital environment that houses the digital poetry explorations draws on a number of modalities. It includes the linking of video clips of the poets offering commentary on their poems and also on poetry and poetry teaching in general, which gives a sense of immediacy not found when reading a poem on the printed page. The power of the poets' commentary cannot be underestimated. As an invaluable layer of meaning added to the work, the annotation is an integral part of the exploration and offers the reader "a guide on the side." The annotations are non-linear and the reader has the choice of whether to take advantage of this additional information or not.

There have been poetry anthologies that have included commentary, most often provided by a literary critic rather than the poet, and the commentary is offered in the margins as it is in this digital environment. However, I know of no anthologies that provide the reader with the opportunity to hear and see the commentary through video clips. Such a multimodal expression of the commentary allows the reader to hear the tone and inflection of the poet, where the pauses and emphases, even the laughter, is placed. In addition, we are able to see the poet's facial expressions and gestures, all of which add layers of meaning to their words. 
Implications for the Classroom

Our students are already immersed in new media, however there is a marked difference between the kinds of texts they typically use in classrooms and those they engage with in their out-of-school lives. Because they are immersed in digital environments, not only on the Internet, but also through their gaming systems, children naturally express themselves in multimodal ways. Indeed, there is already a plethora of digital poetry sites on the Web that could be used in the classroom to inspire students to explore poetry through more contemporary forms of expression. A simple search on YouTube for example, yields more than 78,000 results, much of which is quite useful in the classroom. These are examples of animations or other kinds of performances that students would be able to use as models if they had access to a video camera and/or a web cam, and some simple software, like Photostory or MovieMaker. There is also no shortage of digital poetry websites that feature the work of poets experimenting with new forms, including EPoetry at http://epc.buffalo.edu/e-poetry/ and The Museum of Visual Poetry at http://www.visualpoetry.de/. It would not require any kind of leap for children to create hypermedia or digital poetry, as long as they had the appropriate technology to do so. They already possess the necessary cultural and cognitive tools albeit in a nascent form. If students were given the opportunity to immerse themselves in poetry in the same way that they immerse themselves in other digital environments, it is not hard to imagine that they might experience shifts in thinking about poetry.

One of the main pedagogical aims suggested by the poets in the study for the teaching and learning of poetry is that students need to hear the poem read aloud. In the digital explorations and video discussed here, not only is the poem read aloud by the 
poet, but alternate versions of the reading are also offered so that students can make comparisons and discuss how different readings modify the poem's tone and contribute to an understanding of poem's meaning(s). In this model sound is meaning, which challenges the conventional notion that form and content are separate entities.

The poets also advocate sustained engagement with the poem by entering into a conversation with the poem. In the digital environment students have the opportunity to interact with the poem by playing with line breaks or by altering the poem's structure so that it is viewed in prose or in stanzas where no stanzas originally existed. They can focus only on the nouns or verbs in a poem in an attempt to glean meaning from it or they can consider how images might contribute to the way the poem is received. They might view the many ways the poems or parts of them are performed by others and generate their own ideas about how to perform a poem. All of these activities promote individual response and critical thinking and they encourage students to pay attention.

Lee reminds us that reading and writing are inextricably linked and the best way to learn to write poetry is to immerse oneself in the reading of poetry. Who better to learn from than a working poet who is tangible and offering advice? In an age when more and more authors have their own websites and students have greater access to them via the Internet, there are many opportunities and possibilities when it comes to author/reader interaction. As Gee (2000) points out, in the digital environment, it is not the traditional classroom teacher alone who takes on the "role of the scaffolding, structuring expert," it is also the various technologies and, in this case, the poets themselves who share this role (p. 52). The definition of Vygotsky's (1978) concept of a 'zone of proximal development' - the distance between a student's existing level of 
understanding and the level that can be accomplished in collaboration with others - can be expanded to encompass, not just other people, but also "powerful artefacts" like digital technologies (Gee, p. 52). In fact, Davis, Sumara \& Luce-Kapler (2000) point out that "the use of emergent technologies to create interactive events of learning for students, in the absence of a live teacher, is one of the most active areas of innovation in many formal educational institutions" (p. 251).

Looking ahead

The multimodal poetry explorations used in the research presented here offer one example of what poetry exploration could look like in a digital environment. As a pedagogical model, and with appropriate modifications, the digital environment could be used with students in a classroom context to investigate how it might influence how they think about poetry or how it might change the way they write or perform their own poetry. It could also provide one mode for digitally performing their own poetry. Additional investigations might examine how students create their own digital environments based on a poet of their choice or how they use hypermedia links to annotate a piece of literature.

\section{A Final Word}

I began this research with a concern about the fate of poetry in a digital age. Although I do not believe that poetry needs a gimmick to make it more appealing, I do think that we have suppressed poetry's multimodal nature too long within the confines of the print text. The populist revolution, a distinct move from print to a secondary orality, points to the need to recognize that a change is needed in the way we approach poetry in the classroom. It is easy for me to advocate an infusion of new technologies in the 
English language arts classroom; I have many years of teaching experience and an extensive repertoire of technological skills. I am also cognizant of the need to continue to address such issues as funding, policy, professional development and equity as they relate to educational computing. Despite the challenges, we cannot afford to ignore the digital experience and skills that students now bring to our classrooms. The question is no longer whether we should use digital technologies in the classroom, but rather how new technologies are influencing "the developments of human perception, consciousness, cognition, and sociality" (Davis, Sumara \& Luce-Kapler, 2000).

\section{References}

Armstrong, A. \& Casement, C. (1998). The Child and the Machine: Why Computers May Put Our Children's Education at Risk. Toronto: Key Porter Books Ltd. Collins. B. (2004). Poems on the Page, Poems in the Air. In M. Eleveld (Ed.), The Spoken Word Revolution (pp. 3-7). Naperville, Ill: Sourcebooks, Inc.

Davis, B., Sumara, D. \& Luce-Kapler, R. (2000). Engaging Minds: Learning and Teaching in a Complex World. Mahwah, New Jersey: Lawrence Erlbaum Associates.

Dobson, T. (2005). Technologies of Text: Reflections on Teaching, Learning, and Writing With/in Digital Environments. Journal of the Canadian Association for Curriculum Studies, 3(1), 123-138.

Dresang, E. (1999). Radical Change: Books for Youth in a Digital Age. New York: The H.W. Wilson Company. 
Ellul, J. (1990). The Technological Bluff. Grand Rapids, MI: William B. Eerdmans Pub. Co.

Gee, J.P. (2000). New people in new worlds: networks, the new capitalism and schools. In B. Cope \& M. Kalantzis (Eds.), Multiliteracies: Literacy Learning and the Design of Social Futures (pp. 43-68). New York: Routledge.

Gioia, D. (2004). Disappearing Ink: Poetry at the End of Print Culture. Minnesota: Graywolf Press.

Kellner, D. (2000). Multiple Literacies and Critical Pedagogies: New Paradigms. In P. Trifonas (Ed.), Revolutionary Pedagogies (pp. 196-202). NY: RoutledgeFahmir.

Kress, G. (2003). Literacy in the New Media Age. London: Routledge.

Luce-Kapler, R. (2003) Orality and the Poetics of Curriculum. Journal of the Canadian Association for Curriculum Studies, 1(2), 79-93.

Luce-Kapler, R. \& Sandhu, G. (2002). The Poetics of Digital Space. In R. Hammett \& B. Barrell (Eds.), Digital Expressions: Media Literacy and English Language Arts (pp. 67-85). Calgary: Detselig Enterprises Ltd.

Luke, C. (2003). Pedagogy, Connectivity, Multimodality, and Interdisciplinarity. Reading Research Quarterly, 38(3), 397-403.

Nodelman, P. (1988). Words About Pictures: The Narrative Art of Children's Picture Books. Athens, GA: University of Georgia Press.

O’Connor, J.S. (2004). Wordplaygrounds: Reading, Writing, \& Performing Poetry in the English Classroom. Urbana, Illinois: NCTE.

Ong, W. (1982). Orality and Literacy: The Technologizing of the Word. London: Routledge. 
Pahl, K. \& Rowsell, J. (2005). Literacy and Education: Understanding the New Literacy Studies in the Classroom. London: Paul Chapman.

Sapnar, M. (2005). The Sound of New Media Poetry. Poems That Go. Retrieved on October 7, 2005 from the World Wide Web: http://www.poemsthatgo.com/gallery/spring2003/poems.htm

Stoll, C. (1995). Silicon Snake Oil: Second Thoughts on the Information Highway. New York: Anchor Books.

Sullivan, A. (2000). Notes from a Marine Biologist's Daughter: On the Art and Science of Attention. Harvard Educational Review, 70 (2).

Vygotsky, L. S. (1978). Mind in society: The development of higher psychological processes. Cambridge, MA: Harvard University Press. 